\title{
Mathematical modelling analysis of logistics status and product sales in coastal area
}

\author{
LiMing LiJianYun \\ (Department of Economics, Qinhuangdao Vocational Technical, China)
}

Keywords: logistics; coastal area; product sales; mathematical model

\begin{abstract}
In the coastal areas, the logistics industry and sales industry have taken a great development, and development is very rapid, it is necessary to research the relationship between logistics status and product sales model of coastal areas, and it has an important value in practice. The logistics supply and product sales of coastal area has a certain promotion relationship, quantitative analysis of the relationship between logistics and product sales in the coastal area is studied. Because it can alleviate the load pressure of logistics resources, improve the important role of logistics resource distribution and logistics supply efficiency. The traditional model uses game model for mathematical modelling analysis of logistics status and product sales in coastal area, unbalanced problems of resource allocation between logistics and product sales in the coastal area has occurred. According to this problem, an improved promotion relationship mathematical model of the coastal area of product sales and logistics is proposed based on logistics and logistics distribution computing, logistics resources distribution and product sales promotion model principle is analyzed, uses the data mining technology as a tool, extract the necessary information and knowledge, logistics and product sales promotion and relationship model of coastal areas is constructed, to solve the nonlinear programming model and it can provide the logistics decision function for sales industry, influence factor of logistics to promote product sales in the coastal area is calculated, the game and contain of logistics and product sales in the coastal area are analyzed, the mathematical model is constructed to achieve the best proportion, the logistics service level and return index are taken for comparison, the simulation results show that, can effectively improve the logistics service level, improve logistics gain with this model, improve the throughput gains of logistics and product sales, and it can promote the rapid growth of the logistics industry and the retail industry revenue.
\end{abstract}

\section{Introduction}

The logistics industry and product sales of coastal areas are flourishing, the development is very rapid, relationship between logistics status and product sales model of coastal area should be studied, and it has an important meaning and value. Logistics is constructed based on transport, storage and distribution with the lowest cost to satisfy customer demand, raw materials, semifinished products, finished products and related information are provided by the origin logistics business, the consumption of goods and plan are formed, management of the whole process is implemented with effective logistics business management. Logistics is a system of control of raw materials manufactured goods, finished goods and information, and transfer to intermediate links, reach the physical movement of the customer, the clear objectives of the organization is completed. The logistics distribution system can make decision for the logistics distribution scheme, and the intelligent decision system should establish the logistics distribution scheme firstly, and each decision will produce results or influence the cognitive prediction to a certain degree. Finally, the transmission cost of each project cost of manpower are taken into consideration, the cost is formed as data series, the data series is taken as the index, and the optimum decision system scheme is obtained with the optimum decision system. Obviously, this kind of decision-making system has lower error rate[1-3].

In the coastal areas, the logistics industry and sales industry have taken a great development, and development is very rapid, it is necessary to research the relationship between logistics status and product sales model of coastal areas, and it has an important value in practice. The logistics supply 
and product sales of coastal area has a certain promotion relationship, quantitative analysis of the relationship between logistics and product sales in the coastal area is studied[4]. Because it can alleviate the load pressure of logistics resources, improve the important role of logistics resource distribution and logistics supply efficiency[5]. The traditional model uses game model for mathematical modelling analysis of logistics status and product sales in coastal area, unbalanced problems of resource allocation between logistics and product sales in the coastal area has occurred. According to this problem, an improved promotion relationship mathematical model of the coastal area of product sales and logistics is proposed based on logistics and logistics distribution computing[6], logistics resources distribution and product sales promotion model principle is analyzed, the mathematical model is constructed to achieve the best proportion, the logistics service level and return index are taken for comparison, the simulation results show that, can effectively improve the logistics service level, improve logistics gain with this model, improve the throughput gains of logistics and product sales, and it can promote the rapid growth of the logistics industry and the retail industry revenue. The mathematical model will have big application value in practice.

\section{Principle and relation model construction of logistics and product sales promotion model}

\section{Logistics resource distribution and product sales promotion model principle}

The logistics and product sales promotion model in the coastal area is constructed firstly, and the massive data, scattered, random, the interference data should be processed, extract the information of process knowledge, the potential and valuable data of logistics and product sales are mined. Logistics center of product sales in the coastal area is constructed, the main objects are the management, decision-making layer, the corresponding object relations of logistics and product sales promotion model is shown in Figure 1.

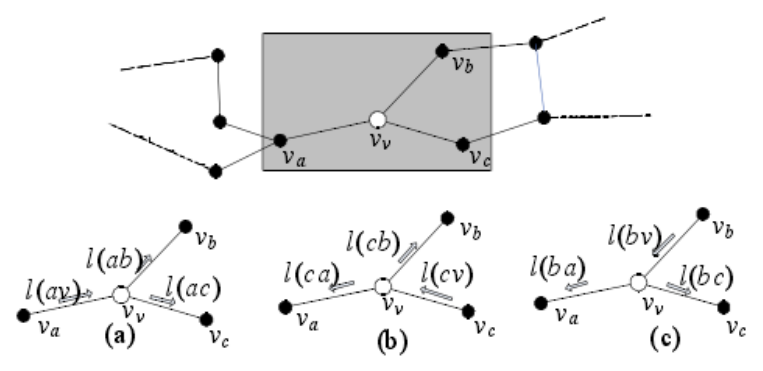

Figure 1. Logistics and product sales promotion model

In Figure 1, logistics resources center is graph model $G=(V, E, W)$, for the nodes u and v, if $(u, v) \in E$, the supply chain node $\mathrm{u}$ is adjacent to the node $\mathrm{v}$, otherwise, $\mathrm{u}$ and $\mathrm{v}$ are not adjacent. If any two of the set $U \subseteq V$, the nodes are not adjacent, then $U$ is called the independent set of graph $G$. If $U$ is an independent set in the graph $G$, the nodes of supply chain network increase, the model of supply chain logistics information sharing based on grid technology is shown in Figure 2.

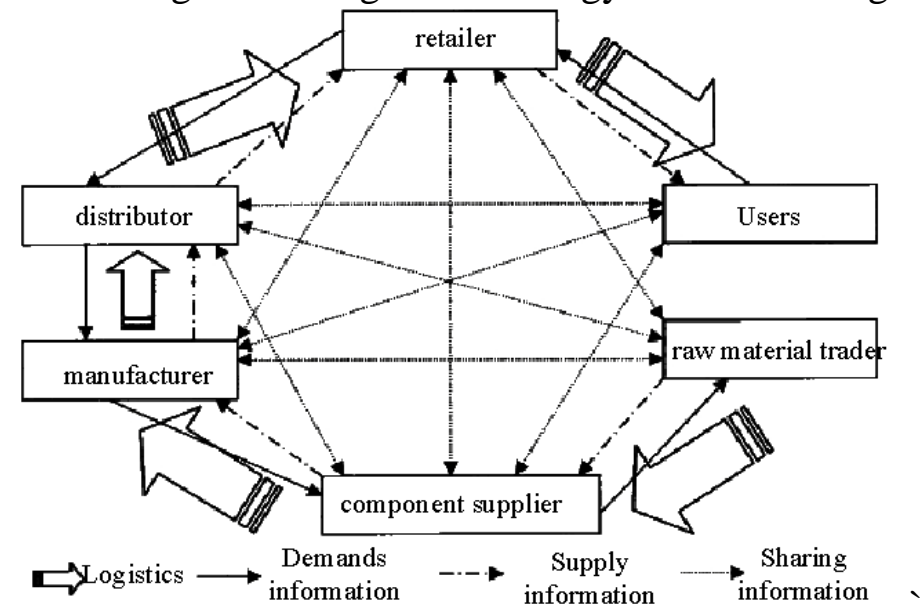

Figure 2. Model of supply chain logistics information sharing 
Logistics resources and logistics center are formed, in the logistics supply chain network model, load capacity of adjacent nodes ${ }^{v_{a}},{ }^{v_{b}}$ and $v_{c}$ is expressed as

$$
l\left(v_{a}\right)=l(b a)+l(c a), l\left(v_{b}\right)=l(a b)+l(c b), l\left(v_{c}\right)=l(a c)+l(b c)
$$

The load capacity of edges is expressed as:

$$
l\left(e_{a v}\right)=l(v a)+l(a v), l\left(e_{b v}\right)=l(v b)+l(b v), \quad l\left(e_{c v}\right)=l(v c)+l(c v)
$$

Thus:

$$
l\left(v_{v}\right)=\left(l\left(e_{a v}\right)+l\left(e_{b v}\right)+l\left(e_{c v}\right)\right) / 2
$$

In the formula, ${ }^{l}\left(e_{a v}\right)=l\left(e_{b v}\right)=l\left(e_{c v}\right)$, and $l\left(v_{v}\right)=3 l\left(e_{a v}\right) / 2$, the hierarchical weighted logistics supply model is researched, and the schematic diagram of the general supply chain network model is constructed, then, the logistics and product sales promotion model of hierarchical network is constructed, when there are free competition logistics resources, consumers choose to buy logistics information depends on consumer utility, contrast relation is determined to purchase two items: if you buy this A product is greater than utility B product, then buy A product, and vice versa buy B products. Comprehensively considering the influence of logistics and logistics speed on consumer price effect, the consumers to buy A products must meet:

$$
\begin{aligned}
& v-p_{1}+\rho_{1} A_{1} \geq 0 \\
& v-p_{1}+\rho_{1} A_{1} \geq \delta \cdot v-p_{2}+\rho_{2} A_{2} \\
& U=\left\{\begin{array}{c}
v \geq p_{1}-\rho_{1} A_{1} \\
v \geq \frac{p_{1}-p_{2}+\rho_{2} A_{2}-\rho_{1} A_{1}}{1-\delta}
\end{array}\right.
\end{aligned}
$$

If consumers choose to buy B products, it should satisfy the constraint condition:

$$
\delta \cdot v-p_{2}+\rho_{2} A_{2} \geq 0
$$

And

$$
v-p_{1}+\rho_{1} A_{1}<\delta \cdot v-p_{2}+\rho_{2} A_{2}
$$

That:

$$
U=\left\{\begin{array}{c}
v \geq \frac{p_{2}-\rho_{2} A_{2}}{\delta} \\
v<\frac{p_{1}-p_{2}+\rho_{2} A_{2}-\rho_{1} A_{1}}{1-\delta}
\end{array}\right.
$$

Each enterprise is fused ion the supply chain competition and cooperation model with the different clustering coefficient. Finally, the supply chain network model is formed, and the effective decision model of logistics industry and sales industry is realized.

\section{Construction of logistics supply chain relationship model}

In the coastal areas, it is necessary to research the relationship between logistics status and product sales model, in the logistics and product supply chain, there are information flow, capital flow, and products flow, the logistics is the core of the whole process, supply, distribution sides are set as the network oriented node of logistics supply chain structure, the purchaser is set to physical nodes, the links are the road, railway, waterway and pipeline in the supply chain, they are edges of network topology structure.

The intelligent logistics decision system of logistics supply chain relationship is constructed, it can provide the initial data for the logistics information, the data mining technology is taken as tool, extract the necessary information such as sales and logistics, logistics and product sales promotion and relationship model of coastal areas is constructed, it meets the following inequality:

$$
p_{2}-\rho_{2} A_{2} \geq \delta \cdot\left(p_{1}-\rho_{1} A_{1}\right)
$$

To maximize social benefits and minimize logistics resource load, and the logistics and product sales output appears the best matching. Namely, the objective function gets the maximum:

$$
Z_{1}=B \sum_{w \in W} q^{w}-\sum_{a \in A} x_{a}\left[t_{a}\left(x_{a}\right)+\beta v_{a}\right], \quad \forall v_{\min } \leq v_{a} \leq v_{\max }
$$

Product sales supplier's decision-making is a very complex process, because the product sales determines whether to purchase and logistics according to the consumer, namely the market only needs for A product demand, when meets the following inequality: 


$$
p_{2}-\rho_{2} A_{2} \leq p_{1}-\rho_{1} A_{1}-Q(1-\delta)
$$

Consumer demand depends on the minimum logistics cost on the w path where the market only has logistics demand to products $\mathrm{B}$, while:

$$
\delta \cdot\left(p_{1}-\rho_{1} A_{1}\right) \leq p_{2}-\rho_{2} A_{2} \leq p_{1}-\rho_{1} A_{1}-Q(1-\delta)
$$

Because of the information providers may not provide the exact logistics and transport information, therefore, we need for the above inequalities for logistics and supply chain solutions respectively:

$$
\begin{gathered}
\frac{p_{1}-p_{2}+\rho_{2} A_{2}-\rho_{1} A_{1}}{1-\delta} \leq v \leq Q \\
\frac{p_{2}-\rho_{2} A_{2}}{\delta} \leq v \leq \frac{p_{1}-p_{2}+\rho_{2} A_{2}-\rho_{1} A_{1}}{1-\delta}
\end{gathered}
$$

Where, $\delta_{a k}^{w}$ is ' $0-1$ ' variable, $\delta_{a k}^{w}=1$ is the adaptive control coefficient of supply chain structure $w$. According to the travel cost (price, information, the main road toll), it describes the transmission performance and the efficiency of decision making of the supply chain network structure, the expression is: $L=\frac{1}{N(N+1) / 2} \sum_{i \geq j} d_{i j}$. Wherein, $d_{i j}$ is the shortest path connecting any two businesses $i$ and $j$. The result determines whether to need to logistics, which along the district sales products, the relationship model and block function is:

$$
\begin{aligned}
\min Z\left(\tilde{\mathbf{f}}, \hat{\mathbf{f}}, \mathbf{q}^{w}\right) & =\sum_{a \in A} \int_{0}^{x_{a}}\left[t_{a}\left(x_{a}\right)+v_{a}\right] d x+\frac{1}{\hat{\theta}} \sum_{w \in W} \sum_{k \in K^{w}} \hat{f}_{k}^{w} \ln \hat{f}_{k}^{w} \\
& +\frac{1}{\tilde{\theta}} \sum_{w \in W} \sum_{k \in K^{w}} \tilde{f}_{k}^{w} \ln \tilde{f}_{k}^{w}-\sum_{w \in W} \int_{0}^{q^{w}} D^{-1}(w) d w
\end{aligned}
$$

St.

$$
\begin{gathered}
\sum_{k \in K^{w}} \hat{f}_{k}^{w}=\eta^{w} q^{w}, w \in W \\
\sum_{k \in K^{w}} \tilde{f}_{k}^{w}=\left(1-\eta^{w}\right) q^{w}, w \in W \\
\hat{f}_{k}^{w} \geq 0, \tilde{f}_{k}^{w} \geq 0 w \in W \\
x_{a}=\sum_{w \in W} \sum_{k \in K^{w}}\left(\hat{f}_{k}^{w}+\tilde{f}_{k}^{w}\right) \delta_{a k}^{w}, a \in A \\
q^{w} \geq 0, w \in W
\end{gathered}
$$

\section{Improved mathematical modelling analysis of logistics status and product sales}

The traditional model uses game model for mathematical modelling analysis of logistics status and product sales in coastal area, unbalanced problems of resource allocation between logistics and product sales in the coastal area has occurred. According to this problem, an improved promotion relationship mathematical model of the coastal area of product sales and logistics is proposed based on logistics and logistics distribution computing, Logistics has impact on consumer utility embodies with the sales growth and consumer preference, the logistics market demand pressures is obtained, the load of logistics products A, B are:

$$
\begin{gathered}
Q_{1}=Q \cdot \int_{\frac{p_{1}-p_{2}+\rho_{2} A_{2}-\rho_{1} A_{1}}{1-\delta}}^{Q} \frac{1}{Q} d v=Q-\frac{p_{1}-p_{2}+\rho_{2} A_{2}-\rho_{1} A_{1}}{1-\delta} \\
Q_{2}=Q \cdot \int_{\frac{p_{1}-p_{2}-\rho_{2}}{\delta}-\delta}^{\frac{p_{2} A_{2}-\rho_{1} A_{1}}{1-\delta}} \frac{1}{Q} d v=\left(\frac{p_{1}-p_{2}+\rho_{2} A_{2}-\rho_{1} A_{1}}{1-\delta}-\frac{p_{2}-\rho_{2} A_{2}}{\delta}\right)
\end{gathered}
$$

The formula reflects the dynamic characteristics of consumers on the basis of logistics factors influencing the changing needs of the market, through the mathematical description, the successful construction of the product market demand function logistics rate influence, for the logistics distribution center location problem, the variable is determined, logistics distribution center is selected as $\mathrm{A}$, the corresponding variable is defined as $W_{k i}(i=1,2, \ldots, 6 ; k=1,2, \ldots, 6)$, amount of products transport is defined as $W_{k i}(i=1,2, \ldots, 6 ; k=1,2, \ldots, 6)$, the distribution of goods is $X_{i j}(i=1,2, \ldots, 6 ; j=1,2, \ldots, 8)$, according to the demand distribution of goods, arrange transportation vehicles and the route. According to the demand distribution of goods, the connection relationship between adjacent nodes 
of the supply chain network, it is expressed as: $C_{i}=\frac{E_{i}}{k_{i}\left(k_{i}-1\right) / 2}$. We can obtained the quantitative QoS function logistics service level, it is:

$$
Q=\frac{C_{1} \sum_{i=1}^{k} \exp \left[-S_{2}\left(V_{i}-\mu\right)^{2}\right]}{1+\exp \left[-S_{1} \sum_{i=1}^{k} w_{i}\left(T_{i}-V_{i}\right)\right]}
$$

Where, $C_{1}, S_{1}, S_{2}$ are constants, $k$ is the number of parameters of supply chain logistics,

$$
V_{i}=\frac{X_{\max }^{i}-X^{i}}{X_{\max }^{i}-X_{\min }^{i}}
$$

In the closed-loop supply chain logistics, extract the necessary information and knowledge, logistics and product sales promotion and relationship model of coastal areas is constructed, the optimal impact factor $V_{T}$ shall satisfy: $\frac{\partial \pi_{T}}{\partial p_{1}}=0, \frac{\partial \pi_{T}}{\partial A_{1}}=0, \frac{\partial \pi_{T}}{\partial p_{2}}=0, \frac{\partial \pi_{T}}{\partial A_{2}}=0$, thus, the mathematical model is constructed to achieve the best proportion.

\section{Simulation results}

In order to test the performance of the model, the simulation is taken, The simulation experiment is taken in the MATLAB7.0 environment, the network model is constructed, in the supply chain network structure $m_{0}=4$, the linear supply chain network structure is composed, according to the different demand conditions in market at the same time, the supply chain related parameters: $Q=200, c_{1}=30, c_{2}=10, c_{r}=2, \mu_{1}=\mu_{2}=0.01, \rho_{1}=\rho_{2}=0.01, \delta=0.8$. the logistics service level and return index are taken for comparison, A product sales prices result with different decision structures and product profit allocation are expressed in Table 1.

Table 1 Product profit allocation with different logistics model in the coastal areas

\begin{tabular}{llll}
\hline Items & $\begin{array}{l}\text { Traditional } \\
\text { game model }\end{array}$ & cooperative & $\begin{array}{l}\text { New } \\
\text { model }\end{array}$ \\
\hline A product sales price & 47.5599 & 49.8288 \\
B product sales price & 25.0703 & 33.5912 \\
A products logistics & 79.0196 & 115.2242 \\
speed & & \\
$\begin{array}{l}\text { B products logistics } \\
\text { speed }\end{array}$ & 73.5207 & 86.1512 \\
$\begin{array}{l}\text { A products demand } \\
\text { B products demand }\end{array}$ & 87.7996 & 120.1205 \\
$\begin{array}{l}\text { A product profit } \\
\text { B product profit }\end{array}$ & 1510.5 & 38.8597 \\
$\begin{array}{l}\text { Total profit of supply } \\
\text { chain }\end{array}$ & 1040.7 & 1793.6 \\
\hline
\end{tabular}

The throughput gains of logistics and product sales are shown in Figure 3, and the convergence property with new method and traditional method is shown in Figure 4. 


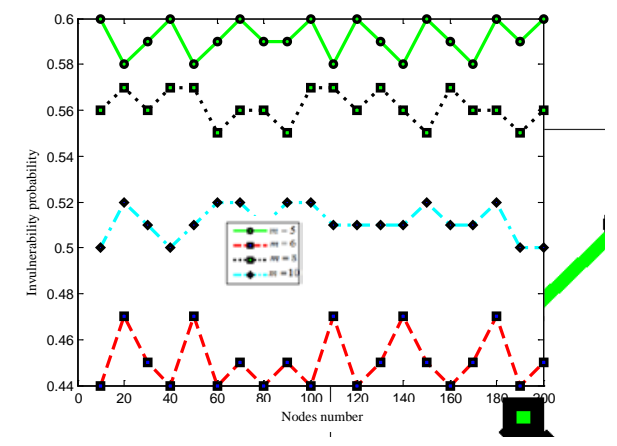

Figure 3 Throughput gains of logistics and product sales

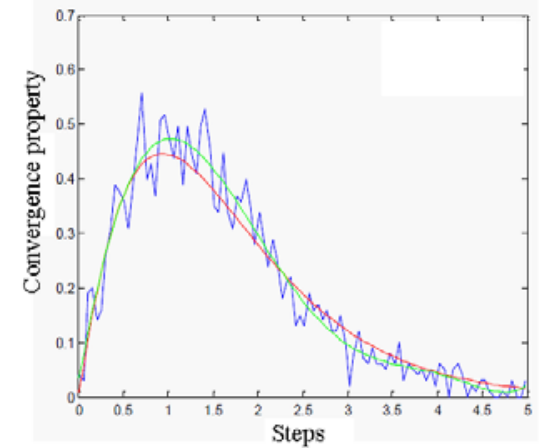

Figure 4. Convergence property comparison

It can be seen from the simulation results, with the new model, it can effectively improve the logistics service level, improve logistics gain with this model, improve the throughput gains of logistics and product sales, convergence property of the mathematical model is better than the traditional method, with the new model proposed in this paper, it can promote the rapid growth of the logistics industry and the retail industry revenue.

\section{Conclusions}

In this paper, an improved promotion relationship mathematical model of the coastal area of product sales and logistics is proposed based on logistics and logistics distribution computing, logistics resources distribution and product sales promotion model principle is analyzed, simulation results show that this model can improve the throughput gains of logistics and product sales, and it can improve the retail industry revenue with the rapid growth of the logistics industry in the coastal areas

\section{References}

[1] RAWAT M, RAWAT K, GHANNOUCHI F M.Adaptive Digital Predistortion of Wireless Power Amplifiers Transmitters Using Dynamic Real-Valued Focused Time-Delay Line Neural Networks [J] . IEEE Transactions on Microwwave Theory And Techniques, 2010,58(1):95104.

[2] Yang X, Pan T, Shen J. On 3G mobile e-commerce platform based on cloud computing[C]. Ubimedia Computing (U-Media), 2010 3rd IEEE International Conference on. IEEE, 2010: 198201

[3] Varshney U. Pervasive healthcare and wireless health monitoring [J]. Mobile Networks and Applications, 2007, 12(2-3): 113-127

[4] Li Z, Wang C, Xu R. Computation offloading to save energy on handheld devices: a partition scheme[C]. Proceedings of the 2001 international conference on Compilers, architecture, and synthesis for embedded systems. ACM, 2001: 238-246 
[5] Cuervo E, Balasubramanian A, Cho D, et al. MAUI: making smartphones last longer with code offload[C]. Proceedings of the 8th international conference on Mobile systems, applications, and services. ACM, 2010: 49-62

[6] Xian C, Lu Y H, Li Z. Adaptive computation offloading for energy conservation on batterypowered systems[C]. Parallel and Distributed Systems, 2007 International Conference on. IEEE, 2007, 2: 1-8 